\title{
Os primórdios da Psiquiatra Infantil e seus reflexos no Brasil
}

\author{
The beginnings of the Child Psychiatry and its reflexes in Brazil
}

\author{
Jorge Luís Ferreira Abrão \\ Universidade Estadual Paulista \\ Brasil
}

\begin{abstract}
Resumo
A psiquiatria infantil é um ramo de especialidade médica bastante recente desenvolvida entre o final do século XIX e o início do século XX. No Brasil esta disciplina desenvolveu-se a partir de meados do século $X X$ inicialmente vinculada a pediatria e a psicanálise. Assim este artigo tem por finalidade demonstrar a constituição da psiquiatria infantil, a partir de um vértice histórico, e seus reflexos no Brasil. Para tal foram analisados os marcos que delimitaram descobertas e ampliações conceituais constitutivos da psiquiatria infantil durante os séculos XIX e $X X$. Na sequência, apresenta-se os acontecimentos mais relevantes que delimitam o surgimento da psiquiatria infantil no Brasil, para finalmente destacar que esta disciplina sofreu direta influência da educação, da pediatria e da psicanálise durante seu processo de constituição no país, influência que perdurou até o início da década de 1980.
\end{abstract}

Palavras-chave: Psiquiatria Infantil; história; Brasil.

\begin{abstract}
Child Psychiatry is a very recent branch of medical specialty forged between the late nineteenth and early twentieth centuries. In Brazil this discipline developed from the middle of the twentieth century initially linked to Pediatrics and Psychoanalysis. Thus, this article aims to demonstrate the constitution of Child Psychiatry, from a historical point of view, and its reflexes in Brazil. To this end, the frameworks that delimited the discoveries and conceptual expansions that constituted Child Psychiatry during the nineteenth and twentieth centuries were analyzed. Afterwards, we present the most relevant events that determine the emergence of child psychiatry in Brazil, to finally point out that this discipline was directly influenced by Education, Pediatrics and Psychoanalysis during its constitution process in the country, an influence that lasted until the early 1980s.
\end{abstract}

Keywords: Child Psychiatry; History; Brazil.

\section{Introdução}

O presente artigo surge com o objetivo de apresentar as principais linhas de desenvolvimento histórico da psiquiatria infantil em um período compreendido entre o início do século XIX a meados do século $X X$, destacando os principais marcos que constituíram essa especialidade, bem como seu reflexo na constituição desta especialidade no Brasil. Trata-se de um estudo histórico, constituído por intermédio de uma extensa revisão bibliográfica, que delimita um campo de intersecção entre 
psiquiatria, psicologia e psicanálise, de tal forma que estas disciplinas se constituíram mutuamente no que concerne a produção de conhecimento relativo a subjetividade da criança.

Com tal finalidade será apresentado inicialmente um percurso que narre os principais marcos constitutivos da psiquiatria infantil, enquanto disciplina autônoma, que tiveram o condão de influenciar, de forma decisiva, não apenas a delimitação desta especialidade, mas também o desenvolvimento de práticas dedicadas ao diagnóstico e tratamento de crianças em momentos posteriores.

Por fins, serão descritos os acontecimentos mais relevantes e as influências mais significativas que possibilitaram a constituição da psiquiatria infantil no Brasil, enquanto disciplina independente da psiquiatria geral, dotada de objeto próprio e práticas específicas.

\section{O surgimento da Psiquiatria Infantil: da profilaxia à nosografia}

Abordar a história da psiquiatria infantil, enquanto ramo autônomo da psiquiatria geral, significa narrar uma história ainda bastante recente no tempo. Sua formalização, enquanto especialidade independente só foi alcançada em 1937, ano em que ocorreu em Paris, o I Congresso de Psiquiatria Infantil. No entanto, antes mesmo de sua formalização como ramo independente na ciência médica, alguns esforços foram empreendidos com a finalidade de retroceder aos anos da infância a preocupação da psiquiatria geral e buscar explicações para as manifestações do sofrimento psíquico que acometiam as crianças.

A princípio, no alvorecer do século XIX a preocupação da psiquiatria com a infância era ainda bastante difusa, de forma tal que o interesse recaia menos na delimitação de quadros nosográficos próprios da criança, e mais em uma tentativa de compreensão da forma pela qual os anos da infância poderiam interferir na psicopatologia do adulto, de tal forma que a preocupação, neste momento, estava voltada predominantemente ao estado mental que poderia ser iniciado na infância. As reflexões de Jaques Donzelot, a partir de uma análise sociológica, caminham nesse sentido.

Compreende-se assim, o nascimento da psiquiatria infantil. Inicialmente ela não é ligada à descoberta de um objeto próprio, de uma patologia mental especificamente infantil. Seu aparecimento decorre das novas ambições da psiquiatria geral, da necessidade de encontrar um pedestal, um alvo onde se possa enraizar, sob a forma de uma pré-síntese, todas as anomalias e patologias do adulto, de designar um possível objeto de intervenção para uma prática que não pretende mais limitar-se a gerir os reclusos, mas sim presidir à inclusão social. O lugar da psiquiatria infantil toma forma no vazio produzido pela procura de uma 
convergência entre os apetites profiláticos dos psiquiatras e as exigências disciplinares dos aparelhos sociais (Donzelot, 1980, pp. 120121 , grifo do autor).

Feita essa consideração, cabe demonstrar o processo de transição que resultou em uma diferenciação cada vez mais nítida entre a psiquiatria geral e a psiquiatria infantil, culminando com a constituição de registros próprios para a psicopatologia da infância de forma independente da nosografia do adulto. Tomando como leme autores que se dedicaram, de forma direta ou indireta, a descrever ou analisar o desenvolvimento histórico da psiquiatria infantil, entre os quais destacam-se: Bercherie (2001), Cirino (2001) Alexander \& Selesnick, (1968), Póstel \& Quétel (1987) e Pessotti (1984), serão abordados os principais elementos que constituem a história deste ramo da ciência médica.

A primeira referência significativa, que pode ser tomada como marco inaugural da psiquiatria infantil data do final do século XVIII, ou mais especificamente em 1798, ocasião em que foi encontrado em uma floresta localizada no Sul da França, na região de Aveyron, um menino mudo e que demonstrava ser surdo em decorrência da ausência de reação as estimulações auditivas. As primeiras observações deste garoto indicavam que:

Não fazia mais do que emitir grunhidos e sons estranhos, não reagia às interpelações nem a fortes ruídos, cheirava tudo o que levava às mãos. Sua locomoção era mais próxima do galope, andando também de quatro, quando alcançava grande velocidade (Banks-Leite \& Galvão, 2000, p. 12).

O menino, que recebeu o pseudônimo de Vitor, foi transferido em 1800, por ordem do ministro do interior da França para o Instituto Nacional dos Surdos-Mudos, tendo sido na ocasião avaliado por Pinel, que apresenta um relatório bastante desanimador, destacando a impossibilidade de educá-lo. "O diagnóstico de Pinel é desolador: Victor não é um indivíduo desprovido de recursos intelectuais por efeito de sua existência peculiar, mas um idiota essencial como os demais idiotas que conhece no asilo de Bicêtre" (Pessotti, 1984, p. 36).

A despeito das perspectivas pouco favoráveis enunciadas por Pinel, Vitor foi admitido em tratamento por um de seus discípulos, o jovem médico Jean-Marc Gaspard Itard, que defendia a ideia de que o menino poderia ser educado e reintegrado à sociedade. Em 1801, Itard (1801/2000) narra seu trabalho junto a Victor, em um relatório que busca descrever a evolução de seu jovem paciente. 0 mérito deste relatório, hoje clássico para a história da psiquiatria infantil e da deficiência intelectual, reside menos nos resultados obtidos com o menino, que foram parcos e limitados, e mais na possibilidade prospectiva que inaugura, ao lançar os "(...) 
fundamentos da teoria da avaliação e da didática atuais na área da deficiência mental" (Pessotti, 1984, p. 41).

Assim, ao cabo de 10 anos sob os cuidados do Instituto Nacional dos SurdosMudos e tendo em vista as limitações de seu progresso e do esgotamento do tratamento moral promovido por Itard, Vitor foi entregue definitivamente aos cuidados de Madame Guérin, governanta que o auxiliou no Instituto (Banks-Leite \& Galvão, 2000).

Alexander e Selesnick (1968), consideram que, na concepção de Itard, o menino demonstrava ser deficiente por não ter sido civilizado por intermédio do contato com humanos, suposição esta que deu sustentação ao seu método terapêutico, que consistia em uma tentativa de educação sistemática do menino, um tratamento circunscrito ao campo da então denominada medicina moral, definida por Isaías Pessoti (1984) como uma expressão genérica empregada para designar as atividades hoje abarcadas pela psicologia clínica e pela psiquiatria, áreas que vieram a se organizar como profissões muito mais tarde.

A história de Vitor guarda grande relevância para a psiquiatria infantil, não só por ter sido o primeiro caso publicado em detalhe, abordando as iniciativas terapêuticas e seus fracassos, mas também possibilitar o descobrimento de novos quadros nosográficos inerentes à psicopatologia infantil. Segundo Póstel \& Quétel, (1987), foi por intermédio do caso do selvagem de Aveyron que Itard descobriu um novo objeto para a psiquiatria: a psicose infantil. Na medida em que a hipótese de deficiência de Vitor pela falta de ser civilizado vem por terra, a psicose infantil começa a encontrar um espaço de cogitação, ideia esta que ganhará concretude apenas no século seguinte.

Seguindo esta linha de raciocínio o trabalho de Itard com Vitor figura como precursor de vários desenvolvimentos e delimitações que vieram a ser forjados na psiquiatria infantil em anos subsequentes. De forma que

Com a constituição do campo da psiquiatria e psicanálise infantil, Victor e seu mestre passam a ser objeto de interesse de representantes dessa área; é assim que Léo Kanner, nos Estados Unidos, descreve, em 1943, o quadro de "autismo infantil precoce", termo emprestado do suíço Bleuler, e aponta Itard como precursor desse domínio de investigação (cf. Kanner, 1960). Pouco mais tarde, o psicanalista Octave Mannoni também escreve um artigo que se tornou um clássico a respeito de Itard, publicado no Temps Moderne (1965), um ano após o aparecimento do livro de L. Malson, As crianças selvagens: mitos ou realidades, no qual os relatórios são novamente publicados. Merece também ser mencionado o livro de H. Lane, The wild boy of Aveyron, de 1976, publicado nos Estados Unidos, que amplia a discussão sobre Itard e o Selvagem, sobretudo no terreno de educação de surdos (Banks-Leite \& Galvão, 2000, pp. 18-19) 
Após o surgimento do marco inaugural da psiquiatria infantil delimitado pelo relatório de Itard, os esforços dos profissionais nesta área gravitaram, por décadas, de forma muito limitada em torno do conceito de retardo mental, de tal feita que toda a psiquiatria voltada a infância no século XIX tinha como ponto de partida ou chegada este quadro nosológico. Segundo Paul Bercherie o período que compreende os três primeiros quartos do século XIX "(...) é exclusivamente consagrado à discussão da noção de retardamento mental, tal como constituída por Esquirol já antes de 1820, sob o nome de idiotia" (Bercherie, 2001, p. 130).

Nesta direção encontramos o trabalho de Édouard Séguin, que, entre as décadas de 1840 a 1880, tornou-se proeminente, enquanto representante da medicina pedagógica, ao propor um modelo educativo de tratamento voltado a recuperação dos idiotas. Em 1843, Édouard Séguin, deixa a França, onde iniciou seu trabalho e refugia-se nos Estados Unidos, deixando, a partir desse momento forte influência do seu trabalho sobre a psiquiatria infantil norte-americana que começava a ser delineada.

Gracias a él, se desarrollaron las escuelas de la costa este de los Estados Unidos, y echó raíces la psiquiatría norteamericana del niño, ya que Seguin, además de los consejos pedagógicos que prodigó, emprendió estudios de medicina y se convirtió en particular, en el médico de la Institución de Syracuse, al lado del doctor Wilbur. Gracias a él, se crearon las nuevas instituciones de Connecticut, Ohio, Pennsylvania, etcétera. Con él, la cuestión etiológica quedó relegada al fondo del projecto pedagógico. Puede decirse que consideró que toda condición psicopatológica grave el niño podía ser corregida y ser accesible al tratamiento médico-pedagógico (Postel \& Quétel, 1987, pp. 516-517).

Em 1846, Édouard Séguin publica seu tratado intitulado "Traitement moral, hygiène et éducation des idiots et des autres enfants arriérés", que versava sobre o diagnóstico da idiotia e sobre e sobre o método de tratamento médico pedagógico. Como constata Pessotti "(...) a importância da confiabilidade do diagnóstico diferencial para a higiene e o tratamento moral é o tema básico de quase um terço do extenso tratado de Séguin" (1984, p. 116).

Em síntese, a contribuição de Édouard Séguin para a delimitação da psiquiatria infantil pode ser assim definida:

Apesar do rigor dos seus princípios e da sua aplicação, esta educação liga o intelectual ao afectivo e faz apelo à autonomia, à iniciativa, ao imaginário, à arte. Se, contrariamente aos Estados Unidos, onde a sua acção goza de um justo reconhecimento, a sua voz não foi ouvida em França. Édouard Séguin continua, sem contestação, o conceptor de um 
método original, o precursor da neuro-psicologia e da reeducação psicomotora. Por seu lado, este homem do terreno esforçou-se por demonstrar, junto dos mais excluídos entre os excluídos, que é o imperialismo da norma pretensamente científica que fecha o horizonte da educabilidade. Lembra que o singular constitui, em matéria educativa, a categoria decisiva (Gardou \& Develay, 2005, p. 37).

Evidencia-se, durante toda a segunda metade do século XIX, o surgimento instituições para o tratamento de crianças idiotas com adoção sistemática do método médico-pedagógico. O ápice desta tendência foi represento pelo trabalho pioneiro do psicólogo e fisiologista Alfred Binet e do médico Théodore Simon, que desenvolveram, entre o final do século XIX e início do século XX, uma escala métrica com a finalidade de aferir quantitativamente os diferentes níveis de inteligência, culminando no desenvolvimento do conceito de idade mental, que foi largamente empregado durante todo o século $X X$.

Eles examinaram milhares de crianças de diferentes idades, aplicando baterias de tarefas de complexidade diversa, estabelecendo, em 1905, a primeira escala de desenvolvimento da inteligência, que passou a servir como critério de admissão e triagem para as classes especiais (Cirino, 2001, p. 85).

O trabalho de Binet e Simon resultou em um crescente interesse na classificação da inteligência e na discriminação de diferentes níveis da escala por eles proposta, resultando em um primeiro modelo classificatório composto por três níveis: idiota, crianças que são incapazes de comunicar-se por intermédio da palavra, imbecil, crianças que não conseguem comunicar-se por meio da escrita, e débil mental, crianças que sabem comunicar-se por meio da palavra e da escrita mas apresentam atraso de mais de dois anos em seus estudos, sem que esse atraso decorra de falta de acesso à escolaridade. Segundo Binet apenas as crianças que estivesses na categoria de débil mental poderiam beneficiar-se do tratamento médico-pedagógico (Grunspun, 1992).

Em síntese, é possível afirmar que, durante todo o século XIX e mesmo no início do século $\mathrm{XX}$, o campo teórico-prático que veio a ser circunscrito pela psiquiatria infantil esteve centrado, quase exclusivamente no estudo da idiotia, como única manifestação psicopatológica possível de ser diferenciada na infância. Por conseguinte, o método de tratamento adotado como regra foi o médico-pedagógico, com todas as variações e adaptações que estiveram presentes nesse período, ou seja, o nascimento da psiquiatria infantil, desde Itard, não pode ser dissociado da educação, condição esta que resultará nos movimentos de higiene mental e orientação infantil conferidos à psiquiatria infantil, inserindo essa especialidade no campo da profilaxia. 
Ainda no final do século XIX, enquanto o modelo médico-pedagógico encontravase em seu apogeu na psiquiatria infantil, começa a surgir na literatura especializada uma preocupação com a psicose na infância, expandindo os interesses da psiquiatria infantil, no entanto, a sua forma de compreensão está diretamente subordinada a psicopatologia do adulto. Para Bercherie, este período:

(...) caracteriza-se pela constituição de uma clínica psiquiátrica da criança que é, essencialmente, o decalque da clínica e da nosologia elaboradas no adulto durante o período correspondente. É a época em que, de fato, se constitui a clínica clássica em psiquiatria do adulto, na direção de uma mutação impressa à abordagem clínica por Falret e seu aluno Morel (Bercherie, 2001, p. 133).

Léo Kanner (1966a), em seu compêndio de Psiquiatria Infantil, destaca o surgimento do interesse pela psicose infantil, mas, ao mesmo tempo, constata que se conhecia muito pouco sobre o tema até então, visto que a atenção estava voltada predominantemente para a deficiência intelectual, fazendo com que os movimentos que caminhavam no sentido de promover uma maior abrangência da psicopatologia infantil fossem um mero decalque da psicopatologia do adulto. Constata ele: "Ni la obra monumental de Kraepelin ni el clássico libro de texto de Bleuler tenían nada que decir sobre la psicopatología de la niñez" (Kanner, 1966a, p. 41).

Tal fato leva a constatação de que nos primórdios da psiquiatria infantil prevaleceu uma forte tendência ao mimetismo, de tal feita que se buscava compreender os transtornos da infância tomando como referência os modelos de diagnóstico empregados na classificação psiquiátrica do adulto. "Os psiquiatras procuravam encontrar, na criança, as síndromes mentais descritas nos adultos, o que impediu a clínica com crianças a se constituir como campo autônomo de prática e de investigação" (Januário \& Tafuri, 2009, p. 544).

Seguindo esta tendência constatada em diversos manuais psiquiátricos do século XIX, inicialmente de forma mais limitada e ao final do período, com uma presença mais expressiva, começa a surgir uma tentativa de classificação na psiquiatria infantil, o que significa dizer que a psiquiatria infantil começa a ganhar novos contornos para além do diagnóstico da deficiência, com as formulações de hipóteses nosológicas que caminham em direção à delimitação da psicose infantil.

Esquirol diferenciou a criança mentalmente defeituosa da criança psicótica em seu livro Maladies Mentales (1838) (...) Wilhelm Griesinger dedicou parte de seu influente livro Pathologie und Therapie der Psychischen Krankheiten (1845) aos problemas psiquiátricos de crianças.... Henry Maudsley, contemporâneo de Griesinger, dedicou trinta páginas do seu livro Physiology and Pathology of the Mind (cerca 
de 1967) à 'Insanidade no começo da Vida' (Alexander \& Selesnick, 1968, p. 479).

Em suma, pode-se constatar que entre o final do século XIX e início do século XX começa a prevalecer uma tentativa de sofisticação nos critérios de diagnóstico psiquiátrico na infância, que ainda estavam majoritariamente subordinados à psicopatologia do adulto, de forma tal que além da idiotia a demência infantis começava a ser considerada. Do ponto de vista do tratamento, as crianças eram abordadas por intermédio de métodos educacionais, tal qual proposto por Griesinger, ou não eram passíveis de tratamento como descrito na obra de Maudsle (Alexander e Selesnic, 1968).

A obra do psiquiatra alemão Emil Kraepelin, "Tratado da psiquiatria", que contou com oito edições publicadas entre 1883 e 1915, figura como marco desta transição.

No que concerne especificamente ao campo das psicoses agudas e crônicas, Kraepelin realiza uma operação nosológica decisiva na compreensão desses fenômenos. Aplicando seu método de observação longitudinal das entidades mórbidas a três tipos clínicos distintos previamente delimitados e aceitos na tradição psiquiátrica - a catatonia de Kahlbaum, a hebefrenia de Hecker e uma forma psicótica delirante, por ele denominada de paranoide - Kraepelin buscará demonstrar que se tratam, em última instância, de diferentes formas clínicas de uma mesma entidade: a demência precoce (...). É assim que a sexta edição do Tratado, de 1899, apresenta a "Demência precoce" como uma doença única, englobando as três entidades previamente descritas, agora a título de diferentes formas clínicas: catatônica, hebefrênica e paranoide (Pereira, 2001, pp. 127-128).

Considerando que os sintomas referidos se manifestavam muito cedo, Kraepelin denominou este quadro de dementia praecox. Deste modo, constata Cirino:

No vasto campo da idiotia - que, até quase o final do século XIX, era considerado o único problema mental infantil - a distinção entre as formas congênitas e as formas adquiridas nos primeiros anos de vida conduziu à nomeação das demências infantis (Cirino, 2001, p. 81).

O reconhecimento da demência precoce por Kraepelin enquanto entidade nosológica diferenciada da idiotia, propiciou uma expansão na identificação clínica deste diagnóstico, estimulando outros autores a descreve-lo de forma mais detalhada. Um exemplo desta expansão é relatado por Bercherie, ao sustentar que as novas "(...) rubricas etiológicas do retardamento, progressivamente vai destacar-se uma entidade particular, que coloca um importante problema conceitual: o que Sancte de Sanctis denomina, desde 1906, como 'demência precocíssima', da qual Heller, no mesmo ano, faz uma descrição autônoma" (Bercherie 2001, p. 135). 
Ainda segundo (Bercherie 2001), Heller no ano de 1908, relata casos de demência infantil caracterizados por sintomas que se diferenciavam da idiotia.

Tratava-se do aparecimento, a partir dos 3-4 anos, em crianças que, até então, haviam tido um desenvolvimento normal, de um estado de morosidade e indiferença, com negativismo, oposição, transtornos afetivos (cólera, ansiedade), seguidos de uma desagregação da linguagem e de diversos transtornos motores bastante característicos: agitação, estereotipias, maneirismos, catatonia, impulsões (Bercherie, 2001, p. 135).

O trabalho de Heller constitui-se em importante avanço para a psiquiatria infantil, na medida em que a descrição por ele proposta foi, em anos subsequentes, aprofundada e incorporada aos modernos manuais de psiquiatria sob a rubrica de Transtorno Desintegrativo da Infância.

\begin{abstract}
Após relatos de casos esporádicos, tais como o do menino selvagem de Aveyron, o termo psicose infantil foi introduzido no começo do século $X X$, quando Heller descreveu uma apresentação clínica que se conhece atualmente como transtorno desintegrativo. Apesar disso, a categoria, como um todo, somente ganhou relevância nos anos 50, com a descrição do autismo por Léo Kanner. Até a CID-9, o autismo e a psicose desintegrativa eram classificados como psicoses infantis. A recente nosografia baseada na fenomenologia descritiva começou a ser aplicada a partir do DSM-III e CID-10 (Mercadante; Gaag \& Schwartzman, 2006, p. 513).
\end{abstract}

Corroborando as descrições de Heller, no ano de 1921, Zappert apresenta conclusões semelhantes ao descrever crianças que, a despeito de apresentarem desenvolvimento normal até a idade aproximada de quatro anos, evoluíam rapidamente para um quadro demencial significativo. Ao relatar suas descobertas Zappert salientou:

(...) los puntos de semejanza entre la enfermedad de Heller y la demencia precoz - que entretanto se había convertido en esquizofrenia - tales como la estereotipia, la impulsividad, las manifestaciones catatónicas, y dió sobre todo lugar destacadísimo a lo que las desasemejaba: la importancia y la precocidad de los trastornos del lenguaje (Póstel \& Quétel, 1987, p. 521).

Foi a partir da década de 1930 que a psiquiatria infantil começou a se desvencilhar da condição de réplica do modelo nosológico proposto para o adulto, constituindo finalmente uma identidade própria. Duas influências concomitantes contribuíram para que a psiquiatria infantil alçasse voo próprio, a colaboração da pediatria e a influência da psicanálise. 
Kanner (1966b), constata que até o início do século XX não havia na pediatria uma preocupação com o estado mental da criança, seus escritos dedicavam-se a sintomatologia e etiologia de doenças orgânicas, e pouco falavam sobre fatores psicológicos, ambientais e intelectuais na constituição destes quadros. "Para la edición de 1928 de uno de los textos de pediatría más leídos, parece como si no existieran los problemas personales de los niños. Pasa por alto los factores emocionales, intelectuales y ambientales" (Kanner, 1966b, p. 46).

No entanto, a partir da década de 1930 evidencia-se uma inversão de perspectiva na pediatria, que passa a considerar de forma mais efetiva a condição psiquiátrica da criança, buscando compreendê-la e integrá-la em suas ações diagnósticas e terapêuticas. Ainda nas palavras de Kanner: "Se podrían citar fácilmente muchos ejemplos de la buena disposición de los pediatras para adoptar los conceptos y los métodos psiquiátricos. Hacia 1930 ya había una enorme cantidad de material informativo" (Kanner, 1966b, p. 47). Na esteira deste raciocínio, e com a finalidade de corroborá-lo, alguns eventos podem ser destacados: em 1935, a Divisão de Educação Psiquiátrica do Comitê Nacional de Higiene Mental organizou em Washington, uma conferência reunindo pediatras e psiquiatras com o intuito de discutir programas de trabalho na área e, a partir de 1936, a Academia Norteamericana de Pediatria passou a interessar-se pelo desenvolvimento da psiquiatria infantil, incorporando conferências sobre o assunto.

Por sua vez a psicanálise de crianças começava a despontar-se como um campo terapêutico bem delimitado e independente, sustentada por intermédio da técnica da análise de crianças através do brincar (Klein, 1932/1997), desenvolveu hipóteses diagnósticas que enfatizavam a importância do aspecto relacional e a influência do fator ambiental na gênese da doença mental.

É dessa apropriação da psicanálise pela psiquiatria funcionalista americana, incentivada sobretudo por Adolf Meyer (1950-1866), de onde provêm os conceitos que estruturam o imenso campo recentemente conquistado pela clínica pedo-psiquiátrica: a noção da patologia das grandes funções, com sua expressão nos transtornos de conduta (Cirino, 2001, p. 89).

Antes mesmo da nomeação do autismo por Kanner, a psicanalista austríaca radicada na Inglaterra Melanie Klein publica, em 1930, o artigo "A importância da formação de símbolos para o desenvolvimento do ego", no qual relata o caso de um menino de quatro anos, diagnosticado na ocasião como esquizofrênico. Sustenta a autora sabre o diagnóstico de seu pequeno paciente: 
Na minha opinião, portanto, a esquizofrenia na infância - e principalmente a presença de traços esquizofrênicos, que é um fenômeno bem mais generalizado - é bem mais comum do que se supõe. (...) Se ampliarmos o uso deste termo da forma como propus, creio que poderíamos classificar a doença de Dick como esquizofrenia (Klein, 1930/1996b, p. 263).

Considerando a sintomatologia do paciente de Melanie Klein na atualidade, seu diagnóstico seria de autismo, tal qual descrito por Kanner. Desta forma, Melanie Klein aproximadamente vinte anos antes de Kanner, abordou um quadro clínico de autismo, sem, contudo, nomeá-lo de forma mais específica, mesmo porque a preocupação desta autora recaia sobre o aspecto terapêutico e apenas, secundariamente, sobre questões diagnósticas (Petot, 1979/1988).

Póstel e Quétel (1987), atribuirão a J. L. Despert a primeira grande descrição de esquizofrenia infantil. Despert, sustentando-se na observação de 29 casos oriundos do Instituto Psiquiátrico de Nova York, realizadas entre os anos de 1930 a 1937, dedicase a traçar um quadro clínico com diferentes variedades sintomáticas, as quais incidem muito precocemente na vida da criança. Uma breve análise de seu estudo permite identificar que as características das crianças observadas guardam muita semelhança com os sintomas que, futuramente, o psiquiatra Léo Kanner descreverá como características do autismo infantil precoce.

Em 1943 o psiquiatra austríaco radicado nos Estados Unidos Léo Kanner publica o artigo intitulado "Autistic Disturbances of Affective Contact", sustentado na observação de onze crianças, sendo oito meninos e três meninas, que apresentavam características atípicas reunidas em três grupos de sintomas: inaptidão para as relações sociais, prejuízo considerável na aquisição e no uso da linguagem e insistência na preservação da rotina. Embora o termo autismo tenha sido empregado na literatura psiquiátrica desde 1911 por Breuler para identificar um sintoma da esquizofrenia em adultos, com esta descrição Kanner utiliza o termo autismo de forma autônoma, diferencia um quadro nosológico próprio da infância, que foi concebido de forma desvinculada da psicopatologia do adulto Desta forma, a apropriação do termo autismo feita por Kanner, coloca a característica de isolamento e retraimento social presente nessas crianças, como elemento nodal de sua descrição psicopatológica, que foi conceituada nos seguintes termos.

The outstanding, "pathognomonic", fundamental disorder is the children's inability to relate themselves in the ordinary way to people and situations from the beginning of life. (...). There is from the start an extreme autistic aloneness that, whenever possible, disregards, ignores, shuts out anything that comes to the child from the outside (Kanner, 1943 , p. 242). 
Do ponto de vista etiológico Léo Kanner foi ambíguo ao identificar possíveis causas do autismo, ora enfatizando a pouca afetividade materna como responsável pela patologia, ora destacando a existência de possíveis causas de origem genética.

Durante os anos 50 e 60 do século passado, houve muita confusão sobre a natureza do autismo e sua etiologia, e a crença mais comum era a de que o autismo era causado por pais não emocionalmente responsivos a seus filhos (a hipótese da "mãe geladeira"). Na maior parte do mundo, tais noções foram abandonadas, ainda que possam ser encontradas em partes da Europa e da América Latina. No início dos anos 60, um crescente corpo de evidências começou a acumular-se, sugerindo que o autismo era um transtorno cerebral presente desde a infância e encontrado em todos os países e grupos socioeconômicos e étnico-raciais investigados (Klin, 2006, p. 54).

Paralelamente ao trabalho de Kanner, o psiquiatra Hans Asperger (1944) publica o trabalho "Die Autistischen Psychopathen: Archiv fur Psychiatrie und Nervenkrankheiten", no qual expõe casos clínicos que em muito assemelhavam-se ao autismo de Kanner. A Síndrome de Asperger ou psicopatia autística infantil, como ficou conhecida na época, apresenta uma manifestação sintomática mais tardia quando comparada aos 36 meses proposta por Kanner, sendo identificada por volta de quatro ou cinco anos segundo o autor. O transtorno da linguagem nas observações de Asperger não é tão severo como no autismo, no entanto há dificuldades na comunicação não verbal, sobretudo no que diz respeito a comunicação social, com significativa inabilidade para compreender as regras que regem a interação social. Em geral essas crianças apresentam capacidade intelectual preservada, com habilidades em áreas específicas, porém dotadas de pouca funcionalidade. Em que pese o fato de Asperger ter apresentado seu estudo em alemão durante a Segunda Guerra Mundial, seu trabalho foi mantido em completo ostracismo até o final da década de 1970 quando foi recuperado e traduzido pela psiquiatra inglesa Lorna Wing (1991).

Lorna Wing (1991) introduz, desta forma, no debate científico o trabalho de Asperger, aproximando-o das ideias de Kanner e, por conseguinte, fomenta a discussão relativa as semelhanças e diferenças entre o autismo infantil de Kanner e a psicopatia autística de Asperger, que poderiam ser entendidas como quadros noológicos independentes ou variantes de uma mesma manifestação psicopatológica. Na concepção de Wing (1991) essas duas descrições devem ser entendidas como variações de um único quadro psicopatológico mais amplo, introduzindo desta forma a ideia que ganhará força anos mais tarde, de espectro do autismo, posicionamento este consagrado na 5a. Edição do DSM, publicada em 2013, ao estabelecer a categoria Transtorno do Espectro do Autismo, desvinculando esses quadros clínicos dos Transtornos Globais de Desenvolvimento. 
Aproximadamente uma década após a apresentação da delimitação clínica do autismo proposto por Léo Kanner e Hans Asperger, o pediatra austríaco Andreas Rett identifica em sua clínica a ocorrência de uma síndrome de incidência precoce que se manifestava em meninas, caraterizada pela presença dos seguintes sintomas: comportamentos autísticos, estereotipias manuais, deficiência intelectual grave, perda da habilidade de comunicação verbal e alterações no crescimento. De acordo com o relato de Rett, as pacientes por ele tratadas, apresentavam um desenvolvimento neuropsicomotor normal durante os seis primeiros meses de vida, aproximadamente, no entanto, no interstício entre seis a dezoito meses, ocorria acentuada perda de interesse pelo meio, estagnação do desenvolvimento e o surgimento dos sintomas descritos acima.

Ainda que Andreas Rett tenha iniciado suas observações acerca deste quadro clínico em meados da década de 1950, seu primeiro trabalho sobre o tema foi publicado apenas em 1966. Em decorrência da limitada circulação de seu artigo, publicado em alemão, essa síndrome somente ganhou expressão no meio médico em 1983, ocasião em que Benget Hagberg (1983), que desde a década de 1960 vinha trabalhando com pacientes que apresentavam sintomas semelhantes, com a colaboração de Jean Aicardi, Karin Dias e Ovídio Ramos publicaram o artigo "A progressive syndrome of autism, dementia, ataxia, and loss of purposeful hand use in girls: Rett's syndrome: Report of 35 cases", no qual destacam a casuística de 35 meninas afetadas pelos sintomas descritos por Rett, atribuindo, pela primeira vez a este quadro clínico a denominação de Síndrome de Rett.

A delimitação do conceito de autismo e, em menor proporção, a descrição da Síndrome de Rett, enquanto entidades noológicas autônomas, próprias da infância e forjadas de forma independente da nosografia psiquiátrica do adulto, podem ser entendidos como um elemento paradigmático que funda a psiquiatria infantil como especialidade autônoma. O reflexo disso é ser observado nas classificações psiquiátricas que começam a surgir a partir da década de 1950, nas quais as classificações e os critérios diagnósticos próprios da psiquiatria infantil foram tomando contornos mais específicos. Além disso, evidencia-se também uma expansão da psiquiatria infantil no que se refere aos seus fundamentos epistemológicos e filosóficos, que resultarão em hipóteses distintas de etiologia para a doença mental na infância.

Desse momento em diante podemos observar uma mudança, com o aparecimento de duas vertentes na Psiquiatria da Infância: uma derivada de Kanner, com todas as influências ambientalistas, funcionalistas e de higiene mental; e outra, derivada da Psiquiatria Francesa nosográfica e classificatória, definindo-se a si própria como "organodinâmica" e com a maior representação no posterior "Tratado de 
Psiquiatria Infantil" de Ajuriaguerra (1977). Essa Psiquiatria infantil de origem francesa é extremamente rica e, embora bastante influenciada pela psicanálise, constrói todo um corpo teórico no qual não se vinculam somente os quadros de retardo mental, que passam a construir um capítulo da nova especialidade, mas também os quadros psicóticos na infância, trazendo os conceitos de psicoses autísticas, desintegrativas e formas marginais, assim como principalmente os quadros neuróticos reacionais e psicossomáticos, todos com uma ênfase bastante intensa nas idéias desenvolvimentistas (Assumpção Jr., 1995, p. 63).

Estas duas tendências na psiquiatria infantil coexistirão com maior ou menor proeminência ao longo dos anos, resultando em formas distintas na produção de conhecimento e desenvolvimento de práticas dedicadas à atenção da criança com transtorno mental. Por um lado, encontra-se uma tendência organicista, fundada no século XIX e revigorada nas últimas décadas do século $X X$, na qual prevalecem hipóteses etiológicas de natureza genética e perspectiva terapêutica predominantemente farmacológica, sendo as abordagens terapêuticas comportamentais empregadas como elemento coadjuvante. Em outra direção, existe na psiquiatria infantil uma tendência psicodinâmica de influência psicanalítica, que teve maior proeminência entre as décadas de 1940 a 1970 e ainda prevalece em alguns setores, que sustenta a importância dos fatores ambientais na gênese da doença mental em concorrência com fatores de natureza orgânica, coerente com essa perspectiva são consideradas outras formas de tratamento além dos psicofármacos, como abordagens psicoterápicas e outras formas de intervenções ambientais.

\section{A Psiquiatria Infantil no Brasil}

No Brasil durante todo o século XIX e as duas primeiras décadas do século XX, não é possível pensar em uma psiquiatria infantil diferenciada do corpo principal da medicina psiquiátrica, ainda em consolidação no país, de tal forma que as referências a infância no contexto da psiquiatria brasileira, neste período, são breves esparsas e de pouca expressão. Dentre estes acontecimentos esporádicos destaca-se o surgimento, em 1927, da tese de Oliveira Ribeiro defendida no Hospital do Juquery intitulada "Encephalopatias Infantis", cuja ênfase recaia sobre a busca da etiologia e o diagnóstico clínico.

O surgimento de práticas institucionais, no campo da psiquiatria, dedicadas ao cuidado da criança no Brasil, datam da década de 1920. Neste contexto, foi criada, no Hospital do Juqueri em São Paulo, um pavilhão destinado ao atendimento de crianças, denominada Seção de Menores Anormais. 
Por longo período, de sua abertura a meado de 1929, sua organização acompanhou as normas da secção masculina. Os menores eram assistidos por médico-alienista, já sobrecarregado com o trabalho de outras enfermarias. A assistência limitava-se, então, aos cuidados médico-higiênicos, sem vislumbre de qualquer medida pedagógica (Baptista, 1938, p. 251).

Em 1929, uma inversão dessa perspectiva institucional de caráter meramente asilar começa a ser observada com o surgimento de práticas pedagógicas introduzidas como elemento coadjuvante no tratamento psiquiátrico de crianças no referido hospital. Por iniciativa de Pacheco e Silva, então diretor do Hospital do Juqueri, o modelo de atendimento à criança foi reformulado, passando a contar com uma ala para trinta crianças internas e um pavilhão escola com capacidade para cinquenta alunos. Esta unidade destinou-se ao atendimento de diversas patologias, como deficiências mentais, epilepsias e demências, que, separadas em grupos recebiam atendimento multidisciplinar. Tal estrutura foi assim descrita em 1938 por Vicente Baptista:

Com a instalação da "Escola Pacheco e Silva" ficou automaticamente criada a seção de menores anormais do "Serviço de Assistência a Psicopatas do Estado de São Paulo". Os pequenos internados foram divididos em dois grandes grupos fundamentais: ineducáveis (idiotas de todos os gêneros, imbecis, epiléticos em marcha para estado demencial, post-encefálicos graves, etc.) e educáveis. Estes, débeis mentais e anômalos com perturbações da moral e do caráter. O pavilhão Asilo foi reservado para o abrigo dos menores ineducáveis; o pavilhão Escola para os educáveis (Baptista, 1938, p. 254).

O trabalho desenvolvido neste pavilhão do Hospital do Juqueri teve repercussão pelo seu pioneirismo, cuja prática foi analisada na dissertação de Pedro Silva, de 1931, intitulada "Assistência aos menores anormais. Subsídios para seu estudo em São Paulo" Segundo a avaliação de Francisco Assumpção Jr.,

É interessante observar-se que a Psiquiatria Infantil do Hospital das Clínicas da Universidade de São Paulo herdeira direta desse Serviço, embora constituída muitos anos depois, não incorporou essa filosofia, revolucionária par a época, mantendo-se dentro de um modelo asilar, excluindo os deficientes mentais da própria nosografia psiquiátrica e, principalmente, privilegiando um modelo eminentemente hospitalocêntrico, isolado das outras áreas do conhecimento humano, abandonando uma abordagem multidisciplinar já buscada nessa ocasião (Assumpção Jr., 1995, p. 49).

Por sua vez, foi criada em 1929 a Escola de Aperfeiçoamento de Belo Horizonte, que comutou com a participação de três educadores europeus: Theorore Simon, Artur 
Perrelet e Léon Walter, e alguns anos depois a russa Helena Antipoff (Gil 1994). Ainda em Belo Horizonte, por iniciativa de Helena Antipoff, surge em 1932 a Associação Pestalozzi e em 1935 o Instituto Pestalozzi, destinado ao atendimento de crianças com qualquer deficiência ou distúrbio mental.

Em 1933 foi criada no Rio de Janeiro a Seção de Ortofrenia e Higiene Mental do Departamento de Educação do Distrito Federal, cuja direção foi atribuída ao médico alagoano e grande entusiasta da psicanálise Arthur Ramos ${ }^{1}$. Esta instituição mantinha clínicas de orientação infantil em escolas da capital federal com a finalidade de fazer o diagnóstico e promover o ajustamento das chamadas "Crianças Problema". A experiência decorrente deste trabalho foi veiculada no livro "A Criança Problema" publicado por Arthur Ramos em 1939.

O trabalho desenvolvido por Arthur Ramos nesta instituição permitiu o surgimento de uma distinção ainda desconhecida na educação brasileira entre criança com problemas emocionais e aquelas que apresentavam deficiência intelectual, que na pedagogia tradicional eram tratadas e forma indiferenciada como criança anormal, cujos reflexos também reverberaram na seara da psiquiatria infantil.

A nossa experiência no exame dos escolares "difíceis" mostrou que havia necessidade de inverter os dados clássicos da criança chamada "anormal". Esta denominação - imprópria em todos os sentidos englobava o grosso das crianças que por várias razões não podiam desempenhar os seus deveres de escolaridade, em paralelo com os outros companheiros, os "normais". (...) A grande maioria, porém podemos dizer os $90 \%$ das crianças tidas como "anormais", verificamos na realidade serem crianças difíceis, "problemas", vítimas de uma série de circunstâncias adversas (...) (Ramos, 1939, p. 13).

Com proposta semelhante foi fundada em 1938 a Clínica de Orientação Infantil do Departamento de Educação do Estado de São Paulo, sob a coordenação de Durval Marcondes $^{2}$, discípulo de Franco da Rocha e adepto da psicanálise, que teve por finalidade promover assistência ao escolar deficitário (Abrão, 2001).

Esta instituição tinha por finalidade atender crianças com dificuldades de aprendizagem a partir de duas formas principais de intervenção, quais sejam:

\footnotetext{
${ }^{1}$ De origem alagoana, Arthur Ramos de Araújo Pereira (1903-1949) formou-se pela Faculdade de Medicina da Bahia. Em 1934, transferiu-se para o Rio de Janeiro, atuando inicialmente como diretor da Seção de Ortofrenia e Higiene Mental. Na condição de precursor da psicanálise de crianças no Brasil, publicou vários trabalhos, entre eles, os mais destacados são A Technica da Psychanalyse Infantil (1933), Educação e Psychanalyse (1934) e A Criança Problema (1939).

2 Durval Bellegarde Marcondes (1899-1981), desde o início de sua vida acadêmica na Faculdade de Medicina de São Paulo, onde se formou em 1924, interessou-se pela psicanálise. Seguindo os passos do mestre e incentivador Franco da Rocha, de quem herdou o gosto e a dedicação pela psicanálise, iniciou o atendimento de pacientes empregando a técnica de Freud nos últimos anos da década de 1920 (Sagawa, 2002).
} 
realização de avaliações multiprofissionais e promoção de modificações ambientais na escola e na família. Para executar essas ações valeu-se de uma equipe multiprofissional composta por pediatra, psiquiatra, assistente social, psicologistas e visitadoras psiquiátricas ${ }^{3}$, que atuavam conjuntamente tendo como referencial teórico a psicanálise. O livro intitulado "Noções gerais de higiene mental da criança", organizado por Durval Marcondes e publicado em 1946, expõe os fundamentos e os resultados deste trabalho.

Ainda em São Paulo, destaca-se, na década de 1940, o nome do Stanislau Krynski, inicialmente atuando na Unidade Infantil do Hospital do Juqueri e, posteriormente, como professor do Departamento de Pediatria da Faculdade de Medicina de São Paulo da USP, onde estruturou seu trabalho no campo da psiquiatria infantil, destacando-se no estudo da deficiência mental e contribuindo diretamente para a criação da APAE (Associação de Pais e Amigos dos Excepcionais) de São Paulo na final da década de 1950.

No Rio de Janeiro foi inaugurado, em 1942, o Hospital Neuropsiquiátrico da Infância em Engenho de Dentro e, em 1953, foi criada, a Clínica de Orientação Infantil vinculada ao Instituto de Psiquiatria da Faculdade Nacional de Medicina da então Universidade do Brasil. Esta instituição, que contou com a presença de Georgio Heuyer em sua inauguração, demonstrando a influência da psiquiatria de língua francesa em sua proposta de atuação, esteve sob a direção de José Affonso Neto e contou com a presença da médica e psicanalista Marialzira Perestrello que foi encarregada da orientação psicológica. A Clínica adotou uma orientação multiprofissional com avaliação psicológica e neuropsiquiátrica, além de orientação pedagógica, que, em conjunto, demonstravam uma orientação psicodinâmica enquanto fundamento filosófico a subsidiar a prática de psiquiatria infantil (Abrão, 2001).

Em São Paulo, em 1956 nova iniciativa para alavancar a psiquiatria infantil surge sob os auspícios da pediatria, nesta ocasião Pedro de Alcântara Marcondes Machado (1901-1979), Professor Cátedra de Clínica Pediátrica e Higiene da Primeira Infância na Faculdade de Medicina de São Paulo da USP, criou o Serviço de Higiene Mental e psiquiatria Infantil no Hospital das Clínicas, que teve como foco não apenas o tratamento clínico-ambulatória das patologias mentais da infância, mas também a adoção de medidas preventivas em saúde mental. Segundo o psiquiatra Oswaldo di Loreto que atupo neste serviço,

Ao novo Serviço chamou-se Setor de Higiene Mental e Psiquiatria Infantil. Mas o professor Pedro de Alcântara pediu-nos, encarecidamente,

\footnotetext{
3 Psicologistas e visitadoras psiquiátricas, conjuntamente, constituem um campo de atuação que circunscreve, na atualidade, atividades que foram definidas em 1962 como atribuição do psicólogo.
} 
que a ênfase fosse colocada na Higiene Mental e não em Psiquiatria Infantil. Não queria que seu pioneirismo afrontasse o professor de Psiquiatria (Loreto, 2004, p. 40).

Para dar exequibilidade a proposta de intervenção psiquiátrica idealizada por Pedro de Alcântara foi formada uma equipe multiprofissional assim composta: Eduardo Marcondes (pediatra), Dulce Marcondes e Oswaldo di Loreto (psiquiatras), Aydil Machado de Queiroz Perez Ramos (psicóloga) e Mina Buzvosky (assistente social).

Ao narrar seu percurso profissional no campo da psicologia no Brasil Aidyl Queiroz Péres-Ramos descreveu a criação do Setor de Higiene Mental e Psiquiatria Infantil do Hospital das Clínicas da Universidade de São Paulo nos seguintes termos:

No período de minha atuação durante cinco anos (1956-1961) na Seção de Higiene Mental posso destacar a contribuição pioneira da então inovadora modalidade de diagnóstico e tratamento multiprofissional dirigida às crianças e a seus familiares atendidos. Pode-se dizer que a primeira equipe interprofissional foi a então criada; composta de um pediatra Eduardo Marcondes Machado; psiquiatras de crianças, Dulce Marcondes Machado e Oswaldo Dante Di Loreto, assistente social Maria Cecília Beviláqua e eu, como psicóloga. Resultava, em consequência, mudança na realização daquela atividade: de interdisciplinar dentro da própria área médica para interprofissional, com a inclusão de outras especialidades não médicas. Além disso, contribuía, também, para que a recém-criada Seção, que, fazendo alusão ao seu próprio nome, Higiene Mental, fosse dirigida aos distúrbios de comportamento da criança, propulsores, em muitos casos, de quadros psicopatológicos definidos. Este objetivo foi apenas no início porque logo generalizou-se, devido ao fluxo de uma clientela advinda também de outras clínicas do Hospital (Pérez-Ramos, 2006, p. 38).

Em 1961, também na Universidade de São Paulo, surge o Serviço de Psiquiatria da Infância e da Adolescência do Hospital das Clínicas, vinculado ao Departamento de Psiquiatria chefiado por Antônio Carlos Pacheco e Silva. A proposta foi idealizada a partir de meados da década de 1950, mas sua implementação foi efetivada a partir do momento em que a psiquiatra Eneida Matarazzo concluiu sua residência em psiquiatria e especialização em psiquiatria infantil, reunindo condições para efetivamente assumiu a liderança dessa iniciativa.

Naquele tempo era costume do Departamento de Psiquiatria colocar um livre-docente como responsável por Setores e Serviços no Instituto de Psiquiatria, por isso o Prof. Carvalhal Ribas ficou como responsável pelo Setor de Psiquiatria Infantil. Eneida Baptistete Matarazzo e o Dr. Julcir Meirelles Penna, o qual trabalhara como pediatra até então, iniciaram o projeto pioneiro de atendimento ambulatorial de menores de até 17 anos, que eram encaminhados para tratamento de distúrbios psíquicos. 
Foi esse o início da institucionalização de um Setor de Psiquiatria Infantil no Instituto de Psiquiatria. Em 1961, foi criado oficialmente o Serviço de Psiquiatria da Infância e da Adolescência (SEPIA), que passou a funcionar em ambulatório próprio e em duas enfermarias, cada uma com 42 leitos. Eneida Baptistete Matarazzo foi quem, na prática, liderou e organizou o Serviço de Psiquiatria Infantil. Mais duas psiquiatras foram contratadas para colaborar nessa atividade: a Dra. Cacilda Cuba dos Santos e a Dra. Edi Navarro (Amaro, 2003, pp.47-48).

Em uma sucinta caracterização desses serviços, sem a pretensão de ser exaustiva, é possível afirmar que o primeiro serviço focado nas ações preventivas abrigadas sob a alcunha de higiene mental e dedicado ao desenvolvimento de práticas psicoterápicas que permitissem abordar os pacientes no âmbito ambulatória., ao passo que o segundo serviço descrito direcionou suas ações em uma proposta descritiva da nosografia psiquiátrica e em praticas de intervenção hospitalar com poucas interações interdisciplinares. Os dois serviços coexistiram de forma independente no sistema de atendimento do Hospital das Clínicas da Universidade de São Paulo, desenvolvendo práticas diversas apesar de correlatas que contribuíram de forma pioneira para a consolidação da psiquiatria infantil enquanto especialidade autônoma no Brasil.

No ano de 1963 foi criada em Porto Alegre a Unidade de Psiquiatria Infantil do Hospital São Pedro, que ficou sob a responsabilidade de Emília Farias e Beatriz Piccoli, esta última psicanalista da Sociedade Psicanalítica de Porto Alegre.

Os marcos históricos descritos acima, tomados como balizas do desenvolvimento histórico da psiquiatria infantil brasileira na primeira metade do século $\mathrm{XX}$, trazem ao menos duas indicações quando analisados em conjunto.

A primeira circunscrita ao campo da profilaxia, com ênfase na avaliação diagnóstica e orientação pedagógica, reservadas aos casos de menor gravidade, cuja principal forma de expressão foram as Clínicas de Orientação Infantil. Cabe lembrar que, neste período histórico a preocupação profilática tomava a cena da psiquiatria brasileira, não se restringindo, portanto, a psiquiatria infantil. Constata Jurandir Freire Costa:

Sobretudo a partir de 1926 os psiquiatras começaram a enunciar suas novas concepções de prevenção. Eles pretendiam tornar a prevenção psiquiátrica similar à prevenção em medicina orgânica A ação terapêutica deveria exercer-se no período pré-patogênico, antes do aparecimento dos sintomas clínicos. Esta concepção leva-os a dedicar um maior interesse à prevenção da saúde mental. Daquele momento em diante, o alvo de cuidado dos psiquiatras passou a ser o indivíduo normal e não o doente. O que interessava era a prevenção e não a cura (Costa, 1976, p. 33). 
No entanto, deve-se salientar que a concepção de prevenção que sustentava o trabalho desenvolvido no âmbito das Clínicas de Orientação Infantil guarda singular diferença em relação as propostas de cunho eugênico que fundamentaram a ideia de profilaxia adotada pela Liga Brasileira de Higiene Mental fundada em 1923 no Rio de Jairo, por exemplo.

Neste sentido, a conotação profilática atribuída à higiene mental, neste período, não trazia em sua proposta de trabalho o signo da eugenia, nos quais o redirecionamento da educação das crianças era apontado como condição essencial para a saúde mental do indivíduo na vida adulta, ao contrário, buscava-se garantindo às crianças a assistência necessária a suas manifestações sintomáticas durante a infância, condição que, potencialmente, concorreria para uma menor vulnerabilidade no que se refere a ocorrência de neuroses na vida adulto.

A segunda, refere-se à adoção de uma prática asilar como proposta de assistência psiquiátrica à criança com transtorno mental, seja por intermédio da criação de instituições de internato ou semi-internato, que foram constituídas até a década de 1960. A escolha pelas práticas asilares, figurava como única alternativa em um período em que as propostas de atendimento ambulatorial com destaque para as modalidades de psicoterapia eram insipientes, ou mesmo inexistentes no país.

A segunda metade da década de 1960, caracteriza-se pelo surgimento de movimentos expressivos, que se tornaram referências na atenção psiquiátrica à criança e, por conseguinte, para o desenvolvimento da psiquiatria infantil brasileira. Por iniciativa de Stanislau Krynski surge, em 1965, a Associação Brasileira de Deficiência Mental e no mesmo período começam a ser criadas comunidades terapêuticas destinadas ao atendimento de criança, em um modelo de contraposição aos grandes manicômios.

Em Porto Alegre foi fundada, em 1965, a Comunidade Terapêutica de Crianças Léo Kanner, capitaneada por Luiz Carlos Osório, primeira instituição do gênero criada no Brasil com a finalidade de atender crianças autistas, psicóticas, neuróticas graves e casos de distúrbios de conduta, que tinha como fundamentos terapêuticos a humanização do atendimento e a ambientoterapia, sem prescindir de outras intervenções psicoterápicas ou medicamentosas que se fizessem necessárias (Osório, 1970). Em Diadema na região metropolitana de São Paulo, no ano de 1968, foi fundada a Comunidade Terapêutica Enfance, capitaneada por Oswaldo Di Loreto e Michael Raines Schwarzschild.

Importante destacar neste contexto que o surgimento de comunidades terapêuticas, capitaneada por jovens psiquiatras que começavam, a partir da década de 1950, a desbravar o campo, ainda inexplorado, da psiquiatria infantil brasileira representou um marco de transição entre um modelo de psiquiatria sustentado em 
internações prolongadas em grandes manicômios e o surgimento de propostas terapêuticas, pautadas no movimento da antipsiquiatria, que incorporavam recursos técnicos advindos do psicodrama e da psicanálise como elementos integrantes do tratamento psiquiátrico, em uma proposta de trabalho que visava diminuir a exclusão social dos pacientes psiquiátricos.

É justamente no contexto da reforma psiquiátrica que encontramos espaço para o surgimento das comunidades terapêuticas, que se constituíram em uma alternativa mais humanizada para o tratamento da doença mental. Segundo Teodoro (2002),

O movimento atual da reforma psiquiátrica brasileira tem como período germinativo a luta mais ampla pela redemocratização do país, na segunda metade da década de 1970. No entanto, duas referências anteriores, embora superadas pela reforma, mantêm relação com o que aconteceria depois. São elas: o modelo das comunidades terapêuticas, antepassado nobre e generoso da reforma, nas palavras de Delgado (op. cit., p. 47), e o movimento da psiquiatria comunitária e preventiva, que institui as ideias de saúde mental (por oposição à doença mental) e de intervenção na comunidade, inclusive com intenção preventiva. A experiência das comunidades terapêuticas, que, no Brasil, vicejou na virada da década de 1960 para a de 1970, tem como ponto de contato com o movimento atual de reforma o fato de ter sido uma reação às estruturas tradicionais do aparato asilar psiquiátrico (Teixeira, 1993, pp. $102,161,163,162)$. Tratava-se, grosso modo, da tentativa de construção, a partir da psicanálise, de um novo modelo discursivo/organizacional que comande e remodele as ações do cotidiano hospitalar. A aplicação da psicanálise consistia em interpretar, por meio das leituras inconscientes", não apenas os pacientes, mas também a instituição e seus profissionais. A psicanálise comparecia, portanto, para tornar instituições e equipes objeto de interpretação e, como afirma o diretor da primeira comunidade terapêutica do Rio de Janeiro, dr. Oswaldo dos Santos, para assinalar que os limites entre saúde e enfermidade mental são muito menos nítidos. A consequência é a de que o psicanalista, que saberia sobre o inconsciente, torna-se o grande modelo identificatório para os demais membros da comunidade terapêutica (Tenório, 2002, pp. 28-29).

A Comunidade Terapêutica Enfance, surge com essa filosofia, inspirada no trabalho de Maxwell Jones, psiquiatra sul-africano radicado na Inglaterra, criador do conceito de comunidade terapêutica. A prática desenvolvida nesta instituição visava inserir a criança em um ambiente social saudável e cuidadosamente orientado, de forma que a ambientoterapia ${ }^{4}$ não se constituía apenas em uma forma humanizada de

\footnotetext{
${ }^{4} \mathrm{~A}$ ambientoterapia pode ser definida como uma conduta terapêutica que envolve todos os elementos do ambiente institucional, tendo em vista que estes elementos exercem algum tipo de influência sobre o paciente. Desta forma, as atividades cotidianas no contexto institucional, quando conduzidas a parti de uma perspectiva terapêutica que valorize o contato humano, ofereça condutas estáveis e possibilite a criação de um espaço democrático, são promotoras de saúde mental.
} 
tratar o paciente, mas sim um mecanismo de tratamento, que se integrava a terapêuticas tradicionais como psicoterapia e administração de psicofármacos.

Em 1970, Maxwell Jones veio ao Brasil para um congresso de psiquiatria e esteve na Comunidade Enfance, conta Di Loreto: "ele nos devolveu a reverência vindo passar dois dias conosco. Ele passou dois dias fascinados e dizia textualmente: 'vocês levaram a prática das ideias comunitárias muito além do que eu consegui levar, porque eu sempre trabalhei com as amarras dadas pelo serviço público!' (Cytrinowicz, 2002, p. 84).

Em 1967, foi fundada, por iniciativa de Stanislau Krynski e Antônio Lefévre, a ABENEPI (Associação Brasileira de Neuropsiquiatria Infantil). Tendo em vista as limitadas iniciativas empreendidas no campo da psiquiatria infantil no Brasil até esta data, a ABENEPI surge como um elemento integrador de forma a congregar várias ações que vinham sendo desenvolvidas de fora isolada em diferentes contextos no país.

Dos breves registros históricos aqui destacados, evidencia-se que a psiquiatria infantil brasileira foi sendo constituída a partir de diversas influências oriundas da neurologia, da pediatria e da psicanálise, de tal forma que, até o início da década de 1960, esta disciplina não dispunha de autonomia sem o suporte de especialidades congêneres.

Tal fato trará problemas futuros de identidade e de formação do psiquiatra da infância que perder-se-á nos meandros da psiquiatria de adultos sem visão desenvolvimentista e do pediatra com formação exclusivamente psicodinâmica, sem o menor conhecimento dos quadros e da nosografia psiquiátrica. Entretanto, é essa visão da Psiquiatria da infância ligada ao aconselhamento, à orientação médico-pedagógica, à higiene social que será a base do movimento brasileiro (Assumpção Jr., 1995, pp. 67-68).

A despeito das críticas apontadas por Francisco Baptista Assumpção Júnior, a psiquiatria infantil brasileira foi constituindo a partir de meados da década de 1950, uma identidade própria, marcada de forma preponderante por um modelo psicodinâmico e social que recebeu forte influência da psicanálise, colocando em segundo plano estudos de natureza nosográfica e farmacológica. Este modelo que se consolidou nas décadas seguintes, estendendo-se até o final dos anos de 1980, longe de significar um retrocesso, como destaca Assumpção Jr. (1995), representou uma tendência condizente com o pensamento majoritário da época, que colocava a psiquiatria infantil brasileira em uma direção preponderantemente clínico-pedagógico e menos voltada aos aspectos descritivos e farmacológicos. 
Uma inversão dessa perspectiva pode ser evidenciada a partir da década de 1990, com o incremento do interesse pelos estudos nosográficos descritivos, investigações genéticas e pesquisas relativas a ação dos psicofármacos na criança, bem como por um arrefecimento da influência da psicanálise no campo da psiquiatria infantil brasileira.

\section{Considerações Finais}

A psiquiatria infantil, enquanto área de especialidade dotada de autonomia no campo da medicina constitui-se de forma efetiva a partir do século $X X$, a despeito de iniciativas isoladas surgidas ao longo do século XIX. Esse processo de diferenciação da psiquiatria geral ocorreu na medida em que a psiquiatria infantil deixou de caracterizar-se como mero mimetismo da psicopatologia do adulto, buscando o desenvolvimento de regras próprias para compreender as manifestações do sofrimento psíquico infantil.

As primeiras delimitações tracejadas pela psiquiatria infantil ficaram circunscritas ao campo do tratamento. Buscou-se com o distanciamento das práticas de cunho meramente asilar, fundadas em uma política eugênica de exclusão social da doença mental (Foucault, 1972/1978), a implementação de abordagens de caráter pedagógico que visavam modificações comportamentais, em casos em que o comprometimento emocional e neurológico era menos agudo.

Dois elementos contribuíram para essa inversão de perspectiva em relação ao tratamento dos pacientes psiquiátricos na infância, entre o final do século XIX e início do século $X X$.

Primeiramente, o surgimento de parâmetros para a aferição da capacidade intelectual da criança, cuja escala de Binet e Simon tornaram-se um paradigma, por intermédio desse tipo de instrumento tornou-se possível diferenciar, com maior clareza, os grupos de pacientes ineducáveis e educáveis, reservando a abordagem pedagógica ao segundo grupo, cujas perspectivas de tratamento mostravam-se mais efetivas. Desta forma, deu-se maior efetividade a uma tendência introduzida na psiquiatria infantil por Jean Itard em 1801, que havia se mostrado pouco efetiva a época.

Em outra perspectiva, a psiquiatria infantil começa alçar voos próprios, a partir do século $X X$, com a adoção de um enfoque desenvolvimentista, que possibilitou avanços significativos para a delimitação de uma nosografia própria da psiquiatria infantil, diferenciada do adulto, que possibilitou a delimitação de quadros clínicos de doenças mentais específicos da infância, como o autismo, a síndrome de Asperger e a síndrome de Rett. 
No Brasil, a inserção da psiquiatria infantil só se fez sentir de forma efetiva a partir do século $X X$, ainda que práticas isoladas, sem grande repercussão, possam ser identificadas em períodos anteriores. As iniciativas de maior destaque da psiquiatria infantil brasileira neste contexto delimita-se, predominantemente, no âmbito da prática clínica e institucional, haja vista que produção teórica neste campo foi bastante restrita ao longo do século $X X$ e os artigos e teses produzidos, em sua grande maioria, consistiam na aplicação ou na adaptação dos modelos produzidos na Europa ou Estado Unidos.

Neste sentido, ao longo do século XX surgiram diversos serviços de assistência psiquiátrica dedicados ao atendimento de crianças nos principais centros urbanos do país, como São Paulo, Rio de Janeiro, Belo Horizonte e Porto Alegre. Essas instituições, de natureza inicialmente asilar, foram gradualmente mudando seu perfil em direção constituindo práticas mais humanizadas, passando pelo modelo de comunidades terapêuticas até chegarem a modelos clínicos ambulatoriais.

As fontes bibliográficas pesquisas indicam a existência de três linhas de influência que se consorciaram durante o desenvolvimento da psiquiatria infantil no Brasil entre as décadas de 1930 a 1980, são elas: a educação, a pediatria e a psicanálise.

As primeiras iniciativas dedicadas ao cuidado da saúde mental da criança, surgidas a partir da década de 1930, tiveram direta relação com a educação por intermédio das clínicas de orientação infantil, que buscavam encontrar alternativas terapêuticas para os desajustamentos escolares, sejam eles de aprendizagem ou comportamental. Era comum, neste período, diferenciar dois grupos de crianças com transtornos mentais, as educáveis, que poderem beneficiar-se de intervenções médico-pedagógicas, e as deficientes, cuja proposta de assistência restringia-se as internações de caráter asilar, com limitadas, ou quase inexistentes, perspectivas terapêuticas. Evidencia-se neste modo de organização da psiquiatria infantil brasileira na década de 1930 a forte influência do modelo médico pedagógico, que se origina nas primeiras iniciativas de Jean Itard e consolidada com o trabalho de Alfred Binet e Théodore Simon. Esta aproximação entre psiquiatria, psicanálise e educação nas primeiras décadas do século $X X$, caracterizou-se por medidas no campo da higiene mental da criança, que se efetivou por intermédio da profilaxia, dedicando maior atenção as manifestações sintomáticas da criança e promovendo ajustes ambientais no contexto familiar e escolar.

Em um segundo momento a pediatria, originalmente dedicada ao cuidado da saúde física da criança passa a interessar-se pelos problemas de ordem psíquica que acometiam a infância, abrindo uma senda que permitiu teorizar, posteriormente, intersecção entre o físico e o psíquico no processo de desenvolvimento e adoecimento 
da criança. Um exemplo desta linha de influência da pediatria na psiquiatria infantil pode ser evidenciado com a criação do Serviço de Higiene Mental e Psiquiatria Infantil do Hospital das Clínicas da Faculdade de Medicina da USP, em 1956, antes mesmo do Departamento de psiquiatria da mesma universidade criar um serviço próprio de atendimento à criança, o que só veio a acontecer em 1961.

Por seu turno a psicanálise, enquanto sistema teórico sobre o desenvolvimento infantil e método psicoterápico voltado a infância, exerceu influência significativa sobre a psiquiatria infantil brasileira, com particular destaque entre as décadas de 1960 a 1980. Em uma fase em que a psiquiatria clássica, fundada em um modelo descritivo e organicista, ainda dispunha de poucos recursos para compreender e tratar a doença mental da criança, a psicanálise, fundada em hipóteses que encontravam no ambiente social e familiar a origem do sofrimento psíquico na infância, possibilitou o desenvolvimento de um vertente ambientalista na psiquiatria infantil brasileira, que ganhou ímpeto, não só em relação a etiologia da doença mental, como também como recurso terapêutico apto a tratá-la, por intermédio de abordagens psicoterápicas. A mencionada influência psicanalítica encontrava-se em plena consonância com o movimento filosófico denominado antipsiquiatria, que a partir da década de 1960 passou a questionar o modelo asilar e de exclusão social que caracterizava a psiquiatria de então. Desta forma, na busca de novas referências a psiquiatria infantil encontrou sua identidade na aproximação com a teoria psicanalítica, tendência essa que perdurou até o final da década de 1060, quando se evidencia uma inversão desta perspectiva, com a crescente demanda pelos psicofármacos.

O percurso histórico aqui apresentado permite visualizar as principais linhas de influências teórico-práticas que balizaram o desenvolvimento da psiquiatria infantil brasileira, sobretudo no período compreendido entre as décadas de 1930 a 1980. Uma análise mais detida sobre as transformações da psiquiatria infantil no país a partir da década de 1990 comporta outros estudos que se hão de encetar.

\section{Referências}

Abrão, J. L. F. (2001). A história da psicanálise de crianças no Brasil. São Paulo: Escuta.

Alexander, F. G. \& Selesnick, S. T. (1968). Desenvolvimentos na psiquiatria infantil. Em F. G. Alexander \& S. T. Selesnick. História da psiquiatria (A. Arruda, Trad.). (pp. 478-495). São Paulo: Ibrasa. (Original publicado em 1966).

Amaro, J. W. F. (2003). A História do Instituto de Psiquiatria do Hospital das Clínicas e do Departamento de Psiquiatria da Faculdade de Medicina da Universidade de São Paulo. Revista de Psiquiatria Clínica, 30(2), 44-71. 
Asperger, H. (1944). Die Autistischen Psychopathen: Archiv fur Psychiatrie und Nervenkrankheiten, Kindesalter, 117(1), 76-136.

Assumpção Jr., F. B. (1995). Psiquiatria infantil brasileira: um esboço histórico. São Paulo: Lemos.

Banks-Leite, L. \& Galvão, I. (2000). Uma introdução à história de Victor do Aveyron e suas repercussões. Em L. Banks-Leite \& I. Galvão (Orgs.). A educação de um selvagem: as experiências pedagógicas de Jean Itard (pp. 11-24). São Paulo: Cortez.

Baptista, V. (1938). Seção de menores anormais do Hospital Central de Juqueri. Arquivos Serviço de Assistência a Psicopatas do Estado de São Paulo, 2(3-4), 251 258.

Bercherie, P. (2001). A clínica psiquiátrica da criança. Em O. Cirino. Psicanálise e psiquiatria com crianças: desenvolvimento ou estrutura (pp. 129-144). Belo Horizonte: Autêntica.

Cirino, O. (2001). Psicanálise e psiquiatria com crianças: desenvolvimento ou estrutura. Belo Horizonte: Autêntica.

Costa, J. F. (1976). História da psiquiatria no Brasil. Rio de Janeiro: Campus.

Cytrinowicz, M. M. (2002). Criança - Enfance: uma trajetória de psiquiatria infantil. São Paulo: Narrativa Um.

Donzelot, J. (1980). A polícia das famílias. Rio de Janeiro: Graal.

Foucault, M. (1978). História da Loucura (J. T. Coelho, Trad.). São Paulo: Perspectiva. (Original publicado em 1972).

Gardou, C. \& Develay, M. (2005). O que as situações de deficiência e a Educação Inclusiva dizem às Ciências da Educação. Revista Lusófona de Educação, 6, 31-45. Recuperado em 20 de agosto de 2018 de https://revistas.ulusofona.pt/index.php/rleducacao/article/view/845

Gil, A. M. V. P. (1994). A inteligência e a metáfora da flor: um estudo de representação social sobre o deficiente mental. Tese de Doutorado, Pontifícia Universidade Católica de São Paulo, São Paulo SP.

Grunspun, H. (1992). Distúrbios Psiquiátricos da criança. São Paulo: Atheneu.

Hagberg, B., Aicardi, J., Dias, K. \& Ramos, O. (1983). A progressive syndrome of autism, dementia, ataxia, and loss of purposeful hand use in girls: Rett's syndrome: report of 35 cases. Annals of Neurology, 14(4), 471-479. 
Itard, J. (2000). Da educação de um homem selvagem ou dos primeiros desenvolvimentos físicos e morais do jovem selvagem do Aveyron. Em L. B. Leite \& I. Galvão (Orgs.). A educação de um selvagem (M. E. Galvão, Trad.). (pp. 117177). São Paulo: Cortez. (Original publicado em 1801).

Januário, L. M. \& Tafuri, M. I. (2009) O sofrimento psíquico grave e a clínica com crianças. Revista Mal-estar e Subjetividade, 9(2), 527-550.

Kanner, L. (1943). Autistic disturbances of a affective contact. Nervous Child, 2, 217250.

Kanner, L. (1966a). Psiquiatría de los adultos y psiquiatría infantil. Em L. Kanner, Psiquiatría infantil (pp. 41-44). Buenos Aires: Editorial Psique.

Kanner, L. (1966b). Psiquiatría infantil y pediatria. Em L. Kanner, Psiquiatría infantil (pp.45-52). Buenos Aires: Editorial Psique.

Klein, M. (1996). A importância da formação de símbolos para o desenvolvimento do ego. Em: M. Klein. Amor, Culpa e Reparação (A. Cardoso Trad.). (pp. 251-264). Rio de Janeiro: Imago. (Original publicado em 1930).

Klein, M. (1997). A psicanálise de crianças (L. P. Chaves, Trad.). Rio de Janeiro: Imago. (Original publicado em 1932).

Klin, A. (2006). Autismo e síndrome de Asperger: uma visão geral. Revista Brasileira de Psiquiatria, 28(1), 53-61.

Loreto, O. (2004). Origem e modo de constituição das moléstias da mente (psicopatogênese). São Paulo: Casa do Psicólogo.

Mercadante, M T., Gaag R. J. V. \& Schwartzman, J. S. (2006). Transtornos invasivos do desenvolvimento não-autísticos: síndrome de Rett, transtorno desintegrativo da infância e transtornos invasivos do desenvolvimento sem outra especificação. Revista Brasileira de Psiquiatria, 28(sup. 1), 512-520.

Marcondes, D. B. (1946). Noções gerais de higiene mental da criança. São Paulo: Martins Editora.

Osório, L. C. (1970). Comunidade terapêutica infanto-juvenil: avaliação de uma experiência. Jornal Brasileiro de Psiquiatria, 19(3-4), 133-152.

Pereira, M. E. C. (2001). Kraepelin e a criação do conceito de Demência Precoce. Revista Latinoamericana de Psicopatologia Fundamental, 4(4), 126-129.

Pérez-Ramos, A. M. Q. (2006). Humanização Hospitalar: Conquistas e desafios na realidade brasileira. Em Academia Paulista de Psicologia (Org.). O legado da psicologia para o desenvolvimento humano (pp. 36-45). Bauru, SP: Gráfica Coelho. 
Pessotti, I. (1984). De ciência mental: da superstição à ciência. São Paulo: EDUSP.

Petot, J. M. (1988). Melanie Klein I: primeiras descobertas e primeiro sistema (M. Levy, N. M. Kon, B. P. Haber, \& M. K. Bilenky, Trad.). São Paulo: Perspectiva. (Original publicado em 1979).

Póstel, J. \& Quétel, C. (1987). Nacimiento de la psiquiatría infantil (destinos de la idiocia, origen de las psicosis). Em J. Póstel \& C. Quétel. Historia de la psiquiatría (pp. 507-525). Cidade do México, México: Fondo de Cultura Económica.

Ramos, A. (1934). Educação e Psychanalyse. São Paulo: Companhia Editora Nacional.

Ramos, A. (1939). A criança-problema. Rio de Janeiro: Casa do Estudante do Brasil.

Ramos, A. (1933). A technica da psychanalyse infantil. Archivos Brasileiros de Hygiene Mental, 1(2),195-205.

Sagawa, R. (2002). Durval Marcondes. Rio de Janeiro: Imago.

Séguin, E. (1846). Traitement moral, hygiène et éducation des idiots et des autres enfants arriérés. Paris: Libraire de L'Académie Royale de Médecine. Recuperado em 10 de janeiro de 2017, de https://ia802205.us.archive.org/30/items/traitementmoral00segugoog/traitement moral00segugoog.pdf.

Tenório, F. (2002). A reforma psiquiátrica brasileira, da década de 1980 aos dias atuais: história e conceitos. História, Ciências, Saúde: Manguinhos, 9(1), 25-59.

Wing, L. (1991). The relationship between Asperger's syndrome and Kanner's autism. Em U. Frith (Ed.). Autism and Asperger syndrome (pp. 93-121). Londres: Cambridge University Press.

\section{Sobre o Autor}

Jorge Luís Ferreira Abrão é psicólogo, doutor em Psicologia Escolar e do Desenvolvimento Humano pelo Instituto de Psicologia da USP, livre-docente em Psicologia Clínica pela UNESP e Professor-associado do Departamento de Psicologia Clínica e do Programa de Pós-Graduação em Psicologia da Faculdade de Ciências e Letras de Assis - UNESP. E-mail: jorge.abrao@unesp.br.

Data de recebimento: 08/07/2019

Data de aceite: 03/02/2020 